\title{
BRASIL DESPUÉS DE LULA: ¿MÁS DE LO MISMO?*
}

Brazil after Lula: more of the same?

\author{
MARISA VON BÜLOW \\ ANTONIO LASSANCE
}

\begin{abstract}
RESUMEN
El tema de mayor destaque en 2010 fueron las elecciones presidenciales. El éxito de la coalición liderada por el PT debe ser comprendido en un contexto de evaluación positiva del gobierno anterior y de optimismo con respecto al futuro. El análisis del primer año de gestión de Dilma Rousseff muestra que el nuevo gobierno se ha caracterizado más por la continuidad que por la innovación, tanto en términos de los actores que participan del gobierno como en términos de políticas públicas. Este texto argumenta que dicha continuidad es producto de una clara estrategia presidencial, pero también es fruto de un complejo escenario económico y político que dificultó que se hicieran cambios más profundos en 2011.
\end{abstract}

Palabras clave: Brasil, elecciones, partidos políticos, presidencialismo, relaciones Ejecutivo-Legislativo.

\begin{abstract}
"The most prominent issue in Brazilian politics in 2010 was the Presidential election. The sucess of the PT-led coalition should be understood in the context of a positive evaluation of the outgoing administration, and of optimism with respect to the future. The analysis of the first year of Dilma Rousseff's government shows that it has been characterized more by continuity than by innovation, both in terms of the actors that participate in it as well as in terms of the contents of public policies. This article argues that this continuity has resulted not only from a clear Presidential strategy, but also from a complex economic and political scenario, which has made it harder to implement big changes in 2011".
\end{abstract}

Key words: Brazil, elections, political parties, presidentialism, Executive-Legislative relations.

* Agradecemos los comentarios y sugerencias de Leany Lemos, Gabriel Santos Elias, Ricardo Gutiérrez y un referee de la Revista de Ciencia Política a una versión anterior de este trabajo. 


\section{INTRODUCCIÓN}

En 2010, por primera vez en la historia de Brasil los electores escogieron a una mujer como Presidenta de la República. También por primera vez llegó al más alto puesto político una persona que fue torturada durante la dictadura militar. Pese a estos importantes cambios, argumentamos en este artículo que la presidenta Dilma Rousseff tiende a ser más "regime manager" que "regime builder", para utilizar la tipología propuesta por Skowronek $(2003 ; 1983)$. Es decir, al menos durante su primer año de gobierno, la gestión de Dilma Rousseff se ha caracterizado más por la continuidad que por la innovación. Primero, porque sigue en el poder fundamentalmente el mismo bloque de fuerzas políticas (y en muchos casos los mismos individuos) que ha gobernado el país desde 2003. Segundo, porque no se han implementado ni defendido cambios fundamentales en términos de programa de gobierno. Este texto argumenta que dicha continuidad es producto de una clara opción política, pero también es fruto de un complejo escenario económico y político que dificultó que se hicieran cambios más profundos en 2011.

La opción política por la continuidad es clara en la medida en que el actual gobierno se identifica como heredero y tributario de la administración anterior. De hecho, la estrategia electoral de la campaña de Dilma Rousseff se basó en la promesa de seguir el rumbo trazado por el gobierno de Luiz Inácio Lula da Silva. El lema de la campaña de Rousseff era "Para que Brasil siga cambiando" y no "Para que Brasil cambie". Indudablemente, esa es una estrategia que tiene mucho sentido en un contexto de evaluación positiva del gobierno saliente y de optimismo con respecto al futuro. Según datos del IPEA de diciembre de 2011, la mayor parte de la población se muestra satisfecha con respecto a la situación económica del país. ${ }^{1}$ Ese optimismo se explica por los resultados de los esfuerzos para superar lo que Fernando Fajnzylber (1989) llamó el síndrome del "casillero vacío", es decir, la dificultad de los países latinoamericanos de lograr simultáneamente crecimiento económico y mayor equidad social. En el caso de Brasil, en la última década disminuyó la desigualdad, cayó el desempleo y el sueldo mínimo creció $66 \%$ en términos reales entre 2002 y 2012 (Ministério da Fazenda, 2012). En 2011, el país superó al Reino Unido y se tornó la sexta economía más grande del mundo.

Sin embargo, la continuidad que marca la presidencia de Dilma Rousseff no se explica solamente por el éxito de las políticas anteriores. También tiene que ver con las dificultades del Poder Ejecutivo para implementar una agenda muy ambiciosa, que necesite de amplios acuerdos internos a la coalición de gobierno y con el Poder Legislativo. Pese a que el gobierno tiene una base de apoyo amplia en el Congreso Nacional, dicha base es extremadamente heterogénea del punto de vista de sus intereses y de sus posiciones ideológicas, lo cual impone altos costos a la construcción de consensos. Así, materias

Pese a la crisis económica internacional, el Índice de Expectativas de las Familias, calculado por el Instituto de Pesquisa Econômica Aplicada, llegó a los 67,2 puntos (en una escala de 0 a 100) en diciembre del 2011. El Índice, que empezó a ser medido en agosto del 2010, muestra que el optimismo es moderado pero persistente (IPEA, 2012). Ese resultado es consistente con los datos del Latinobarómetro, en los cuales Brasil aparece como el único país de América Latina donde la mayor parte de los entrevistados (54\%) apuesta en un incremento de la renta familiar, y el $64 \%$ es optimista con respecto a la economía (Latinobarómetro, 2011). 
importantes como la reforma del sistema de pensiones, de la legislación laboral, del sistema político o del sistema tributario - para mencionar algunas de las más citadas en el debate político- no fueron parte de la agenda legislativa del Poder Ejecutivo en el 2011.

El énfasis en la continuidad no significa, sin embargo, que no hubo algunos cambios importantes. De hecho, hay diferencias notables en los estilos presidenciales de gestión de Luiz Inácio Lula da Silva y Dilma Rousseff. Además, como veremos más adelante, en algunas áreas de políticas públicas hubo innovaciones puntuales que merecen ser mencionadas.

Este artículo está dividido en dos partes. La primera presenta los resultados de las elecciones realizadas en 2010, cuando se eligió una nueva presidenta, nuevos gobernadores de estados, diputados federales y senadores. Los resultados de las elecciones presidenciales dan cuenta del éxito de la transferencia de votos de un presidente y un gobierno muy populares hacia una candidata que hasta entonces era muy poco conocida por el público. La segunda parte ofrece un análisis preliminar del primer año de gobierno de Dilma Rousseff, a partir de datos sobre las iniciativas del Poder Ejecutivo.

\section{LOS RESULTADOS DE LAS ELECCIONES DE 2010}

El 31 de octubre del 2010, una candidata que nunca antes se había presentado en elecciones fue elegida la primera mujer presidenta, conquistando 55,8 millones de votos. ${ }^{2}$ Las elecciones de ese año representan un marco en la historia de Brasil y un momento más en una sucesión de elecciones que, desde 1989, producen resultados confiables y permiten solidificar las instituciones democráticas brasileñas.

La Tabla 1 resume los resultados de las elecciones presidenciales. Es importante aclarar que, en Brasil, el voto es obligatorio y, en los casos de elecciones mayoritarias (para presidente, gobernadores de estados y alcaldes de ciudades con más de 200 mil electores), se realizan dos vueltas, a menos que un candidato logre obtener más del $50 \%$ de los votos válidos en la primera ronda. Ése no fue el caso en la última elección, en buena medida por el éxito de la candidatura de Marina Silva, por el Partido Verde (PV), que terminó en tercer lugar con casi el 20\% de los votos en la primera vuelta.

Llama la atención, en los datos presentados en la Tabla 1, la concentración de votos en pocos candidatos, especialmente si nos acordamos que, en un pasado no muy distante, el escenario electoral era mucho más fragmentado. En 2010 se presentaron 9 candidatos y 2 obtuvieron prácticamente el $80 \%$ de los votos en la primera vuelta, mientras que en las elecciones de 1989 se habían presentado 22 candidatos y el 80\% de las preferencias estuvieron distribuidas en 5 candidaturas diferentes. Es posible, por lo tanto, referirse a un proceso de simplificación de las elecciones presidenciales, que se ha dado de manera

2 Dilma Rousseff inició su activismo político como militante estudiantil y en la clandestinidad durante la dictadura militar (que en Brasil duró de 1964 a 1985). En el período democrático ocupó puestos directivos en el gobierno del estado de Río Grande del Sur. En 2003 fue Ministra de Minas y Energía del primer gobierno de Lula y después Jefe de la Casa Civil (con estatus de Ministra, encargada del trabajo de coordinación de ministerios y de control de los actos normativos expedidos por el Presidente). 
progresiva desde la democratización del país. Ese proceso ha ocurrido alrededor de una polarización entre los candidatos de dos alianzas partidarias amplias, lideradas por el PT y por el PSDB, que han salido exitosas en las últimas cinco elecciones. Esos resultados han llevado a algunos analistas a hablar de elecciones "bipartidarias" (Limongi y Cortez, 2010; Meneghello, 2007; Melo, 2007). En efecto, desde la transición a la democracia, el PT y el PSDB fueron los únicos partidos que presentaron candidatos propios a presidente en todas las elecciones y, desde 1994, han recibido, entre ambos, al menos el 69\% de los votos válidos en la primera vuelta (ver Gráfico 1).

Sin embargo, es importante enfatizar que no se trata simplemente de dos partidos políticos en disputa, sino de la construcción de alianzas de apoyo a candidatos, en las cuales el PT y el PSDB han podido definir el nombre del candidato presidencial pero no han sido hegemónicos. Esas alianzas han sido caracterizadas por la fluidez en términos de lealtad política y por la heterogeneidad en términos de identidad programática. Como veremos en la siguiente sección, es muy importante tener esto en cuenta para comprender los desafíos de gobernabilidad que se imponen.

Tabla 1: Resultados de las Elecciones Presidenciales 2010, primera y segunda vuelta

\begin{tabular}{|c|c|c|c|c|c|}
\hline \multirow{3}{*}{$\begin{array}{l}\text { Candidato(a) y } \\
\text { Partido Político }\end{array}$} & \multirow{3}{*}{ Alianza } & \multicolumn{4}{|c|}{ Resultados } \\
\hline & & \multicolumn{2}{|c|}{$\begin{array}{c}\text { Primera Vuelta } \\
(3 / 10 / 2010)\end{array}$} & \multicolumn{2}{|c|}{$\begin{array}{l}\text { Segunda Vuelta } \\
(31 / 10 / 2010)\end{array}$} \\
\hline & & Total & $\begin{array}{l}\% \text { votos } \\
\text { válidos }\end{array}$ & Total & $\begin{array}{l}\% \text { votos } \\
\text { válidos }\end{array}$ \\
\hline Dilma Rousseff (PT) & $\begin{array}{l}\text { Para o Brasil seguir } \\
\text { mudando }\end{array}$ & 47.651 .434 & 46,91 & 55.752 .529 & 56,05 \\
\hline José Serra (PSDB) & O Brasil pode mais & 33.132 .283 & 32,61 & 43.711 .388 & 43,95 \\
\hline Marina Silva (PV) & - & 19.636 .359 & 19,33 & & \\
\hline $\begin{array}{l}\text { Plínio de Arruda } \\
\text { Sampaio (PSOL) }\end{array}$ & - & 886.816 & 0,87 & & \\
\hline Otros & - & 283,261 & 0,28 & & \\
\hline \multirow{2}{*}{\multicolumn{2}{|c|}{ Total de Votos Válidos }} & 101.590 .153 & 100 & 99.463 .917 & 100 \\
\hline & & & $\begin{array}{l}\% \text { total } \\
\text { de votos }\end{array}$ & & $\begin{array}{c}\% \text { total } \\
\text { de votos }\end{array}$ \\
\hline Votos en Blanco & & 3.479 .340 & 3,13 & 2.452 .597 & 2,30 \\
\hline \multirow[t]{2}{*}{ Votos Nulos } & & 6.124 .254 & 5,50 & 4.689 .428 & 4,40 \\
\hline & & & $\begin{array}{l}\% \text { total de } \\
\text { electores }\end{array}$ & & $\begin{array}{c}\% \text { total de } \\
\text { electores }\end{array}$ \\
\hline Abstención & & 24.610 .296 & 18,12 & 29.197.152 & 21,50 \\
\hline Total de Electores & & 135.804 .433 & 100 & 135.804 .433 & 100 \\
\hline
\end{tabular}

Fuente: www.tse.jus.br (página oficial del Tribunal Superior Electoral de Brasil). [Consulta: 14-02-2012]. 
Gráfico 1: Porcentaje de Votos Válidos de Candidatos de Alianzas Lideradas por el PT y el PSDB en Elecciones Presidenciales (primera vuelta), 1989-2010

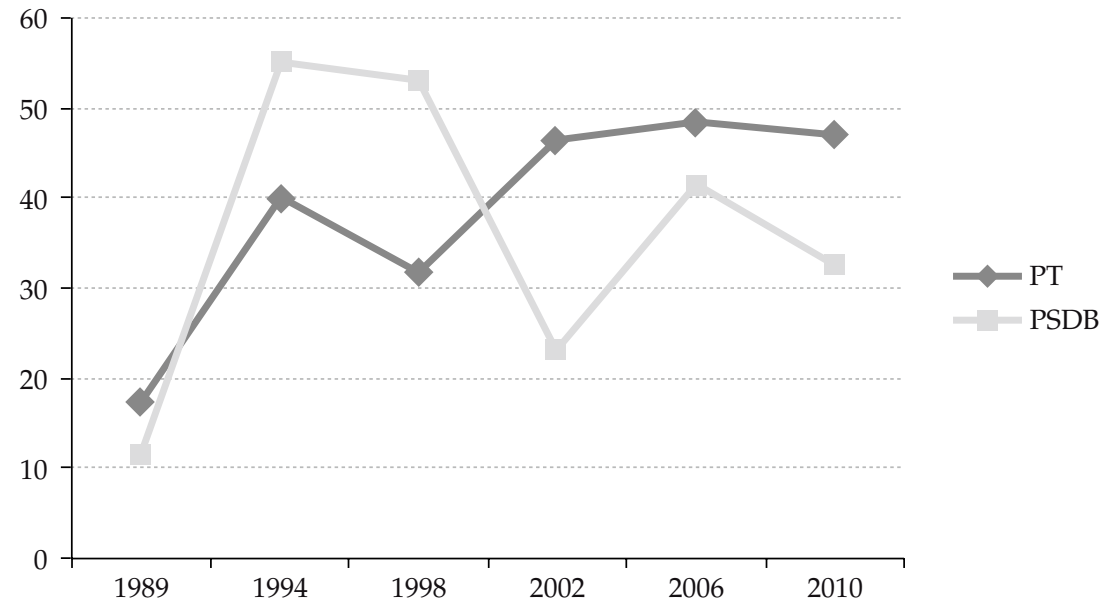

Fuente: elaboración propia con base en datos del Tribunal Superior Electoral (www.tse.jus.br). [Consulta: 14-02-2012].

¿Cómo se explica el éxito de Dilma Rousseff, una candidata que nunca antes se había presentado a una elección? Los análisis sobre los resultados de las elecciones presidenciales de 2010 han enfatizado las siguientes variables: la evaluación positiva del gobierno anterior (con el cual se asociaba directamente) y la percepción optimista de movilidad ascendiente de una parte importante de los electores. Sobre lo primero, en septiembre del 2010, un mes antes de las elecciones, una encuesta de opinión pública mostraba que los niveles de aprobación del gobierno de Lula eran muy elevados: nada menos que el $77 \%$ de los encuestados pensaban que su gobierno era bueno o excelente, $14 \%$ que era "regular" y solamente el $4 \%$ lo evaluó como "malo/terrible" (1\% no contestó) (Datafolha, 2010). Seis meses antes, otra encuesta preguntaba si los electores votarían por la candidata del presidente Lula. El 40\% de los encuestados contestó que sí y el 27\% que "quizás". Preguntados por sus preferencias, el 73\% contestó en ese entonces que no prefería a Dilma Rousseff como candidata; pero, de estos, el 19\% dijo que votaría de todas maneras por el candidato indicado por el presidente Lula (Fleischer, 2010).

Para Peixoto y Rennó, la percepción de movilidad social ascendiente de los electores en el momento de decidir resulta especialmente importante para explicar el voto por la candidata Dilma Rousseff. En la encuesta electoral de 2010, la mayoría de los entrevistados -alrededor del 55\%- percibió una ascensión social en comparación con los ocho años anteriores. Solamente el 7,5\% contestó que había tenido una movilidad descendiente y el 37,5\% argumentó que estaba igual que antes de la "era Lula" (Peixoto y Rennó 2011: 312).

Quizás por esa expectativa positiva respecto a la economía del país, la crisis económica internacional no fue un tema central en los debates electorales. Tampoco fueron 
centrales los temas de políticas públicas. Dos temas tuvieron especial importancia en los acalorados debates que se dieron en los meses anteriores a la elección: el tema de la religión y el de la ética.

Según Pierucci (2011), en Brasil nunca hubo una elección presidencial en que el tema religioso fuera tan importante como en 2011. Tres días antes de la segunda vuelta, el propio Papa Benedicto XVI entró en la campaña al promover una reunión con obispos brasileños y pedirles que orientaran a sus fieles a votar considerando el "bien común", con énfasis en el tema del "derecho a la vida", una clara referencia a la polémica alrededor de la descriminalización del aborto. Sin embargo, el uso del tema religioso pudo haber perjudicado al candidato José Serra, quien terminó visto por los electores más conservadores como haciendo uso meramente instrumental del tema, sin convicción personal. Como sugiere Pierucci, Serra sufrió el "efecto fariseo", por el cual el uso de la religiosidad del candidato termina siendo visto como falso o exagerado por el electorado. ${ }^{3}$ De acuerdo con esa perspectiva, su trayectoria previa como ministro de Salud que apoyó la reglamentación de la práctica del aborto (en los casos previstos por la ley) y las denuncias de que supuestamente su propia mujer había practicado un aborto damnificaron la imagen religiosa que se pretendía proyectar.

El tema de la ética, siempre tan presente en las elecciones presidenciales, entró por la vía más común -la de los escándalos, que afectaron sobre todo a la candidata oficialista, ${ }^{4}-$ pero también por una vía diferente, gracias a la aprobación, en junio del 2010, de la ley que fue conocida como "Ley de la Ficha Limpia". Esa ley tiene una trayectoria peculiar, ya que es una de las pocas leyes de iniciativa popular ${ }^{5}$ aprobadas en Brasil desde la promulgación de la Constitución de 1988, fruto de tres años de trabajo de un amplio grupo de organizaciones de la sociedad civil. Ese conjunto de actores logró reunir un millón seiscientas mil firmas de apoyo a un proyecto que determinó que no pueden ser candidatos aquellos individuos que fueron condenados por crímenes graves, o aún aquellos que no hayan sido condenados pero que estén enfrentando procesos en su contra. También impide la candidatura de aquellos condenados por compra de votos y de los políticos que dejaron sus puestos acusados de irregularidades.

El debate sobre la aplicación de la ley de la "Ficha Limpia" en las elecciones del 2010 llevó a una confusión jurídica de grandes proporciones, ya que no había acuerdo en los tribunales sobre su constitucionalidad. Por varios meses cientos de candidaturas fueron cuestionadas, pero al final se decidió que la ley sólo tendría validez para las

3 El "efecto fariseo" está inspirado en una parábola de la Biblia que diferencia el fariseo de los fieles más humildes. El término fue cuñado por Powell y Neiva (2006) en su análisis sobre el caso estadounidense y es utilizado por Pierucci (2011) para describir lo que pasó en las elecciones de Brasil.

4 En especial, las acusaciones de tráfico de influencia en contra de la ex asesora y sucesora de Dilma Rousseff en la Casa Civil en el mes anterior a la votación.

5 La población puede presentar proyectos de ley de iniciativa popular al Poder Legislativo siempre y cuando ese proyecto sea apoyado por el mínimo de $1 \%$ del electorado del país, el que debe demostrar su apoyo por medio de firmas acompañadas por el nombre completo, la dirección, el número del registro electoral y el lugar de votación. Esas firmas tienen que estar distribuidas por un mínimo de 5 Estados. Aún cuando se logre cumplir con todos esos requisitos, sin embargo, no hay garantías de que el proyecto sea aprobado por el Poder Legislativo y sancionado por el Presidente de la República. 
siguientes elecciones (en 2012). Esa situación de incertidumbre e inseguridad afectó sobre todo las elecciones de gobernadores y de parlamentarios. Pese a los problemas de implementación, para algunos analistas políticos, para el presidente del Superior Tribunal Electoral y para el Movimiento de Combate a la Corrupción Electoral, la nueva ley significa una verdadera "revolución" en el sentido de la moralización de la política del país (Fleischer, 2011).

Si las elecciones presidenciales registran una tendencia a la polarización PT-PSDB, esto no necesariamente se repite en las disputas a nivel de estados y de municipios. Entre 1990 y 2010, el promedio del número de candidaturas para el gobierno de los estados es 5,5, mientras que el promedio de número de partidos que participan en al menos una elección en ese nivel es muy elevado: 24 (Limongi y Cortez, 2010: 30). Sin embargo, Limongi y Cortez señalan que también en los estados hay una tendencia a la polarización entre dos fuerzas políticas en la primera vuelta electoral, cuando son decididas muchas de las contiendas. De hecho, en 1994 hubo 18 elecciones que pasaron a segunda vuelta, pero ese número cayó a sólo 9 en 2010 (idem). Lo importante es que no siempre las dos fuerzas polarizadoras son las mismas que en el nivel de las elecciones presidenciales. Como muestran los datos de la Tabla 2, el PMDB y el PSB son fuerzas políticas importantes en el nivel de los estados, mientras que el DEM ha perdido espacio desde 1990.

Como se argumentó anteriormente, el cuadro de relativa simplificación de las ofertas electorales en la elección de gobernadores y presidente no se reproduce en las elecciones para la Cámara de Diputados. Más bien sucede todo lo contrario, ya que la tendencia a la dispersión de votos por los partidos políticos se ha incrementado en las últimas elecciones. En términos de número de partidos representados en la Cámara de Diputados, en las elecciones del 2002 fueron 19, en 2006 ese número subió a 21 y en 2010 alcanzó 22. En términos de la distribución de votos, desde 1988 ningún partido logra elegir sólo más de 20\% del total de diputados (Lemos, 2010) y los datos muestran que en 2010 esa tendencia a la fragmentación se profundizó. De los partidos más grandes, solamente el

Tabla 2: Votos para Elección de Gobernadores, por Partido, \% de Votos y Número de Gobernadores Elegidos, 1990-2010

\begin{tabular}{|c|c|c|c|c|c|c|c|c|c|c|c|c|}
\hline \multirow{3}{*}{ Año } & \multicolumn{12}{|c|}{ Partido } \\
\hline & \multicolumn{2}{|c|}{ PT } & \multicolumn{2}{|c|}{ PSB } & \multicolumn{2}{|c|}{ PMDB } & \multicolumn{2}{|c|}{ PSDB } & \multicolumn{2}{|c|}{ PFL/DEM } & \multicolumn{2}{|c|}{ Otros } \\
\hline & $\%$ & Núm. & $\%$ & Núm. & $\%$ & Núm. & $\%$ & Núm. & $\%$ & Núm. & $\%$ & Núm \\
\hline 1990 & 9,7 & 0 & 0,5 & 0 & 22,2 & 7 & 11,6 & 1 & 10,8 & 8 & 45,3 & 11 \\
\hline 1994 & 11,7 & 2 & 2,4 & 2 & 17,5 & 9 & 23,2 & 5 & 6,8 & 2 & 38,5 & 7 \\
\hline 1998 & 14,1 & 3 & 2,9 & 2 & 22,9 & 6 & 19,9 & 7 & 15,3 & 6 & 24,6 & 3 \\
\hline 2002 & 27,6 & 3 & 10,1 & 4 & 12,9 & 5 & 22,9 & 7 & 7,2 & 4 & 19,3 & 4 \\
\hline 2006 & 21,9 & 5 & 5,8 & 3 & 18,0 & 7 & 30,1 & 6 & 7,8 & 1 & 16,3 & 5 \\
\hline 2010 & 20,1 & 5 & 11,5 & 6 & 18,2 & 5 & 28,9 & 8 & 4,2 & 2 & 16,9 & 1 \\
\hline
\end{tabular}

Fuente: Limongi y Cortez (2010: 32). 
PT y el PSB lograron aumentar sus bancadas, mientras que 17 partidos eligieron a más del $42 \%$ del total de los diputados (ver Gráfico 2).

En el caso del Senado Federal, en 2010 fueron puestas a disposición del electorado 54 bancas (dos tercios de renovación). Solamente 17 senadores de los 29 que decidieron candidatearse lograron reelegirse. A principios del 2011 estaban representados trece partidos políticos en el Senado, es decir, la fragmentación partidaria era menor que en la Cámara aunque persistente. ${ }^{6}$

Los diez partidos que compusieron la coalición electoral ${ }^{7}$ que apoyó a Dilma Rousseff lograron elegir a 311 de los 513 diputados federales, esto es, poco más del $60 \%$ del total. En las elecciones para senadores, fueron derrotados algunos de los principales líderes de la oposición durante los ocho años de gobierno Lula, gracias a una estrategia exitosa de la campaña del bloque del PT (Fleischer, 2010: 11). ${ }^{8}$ Considerando los nuevos

\section{Gráfico 2: Bancadas Partidarias en la Cámara de Diputados} (elecciones de 2002, 2006 y 2010, \% del total de diputados)

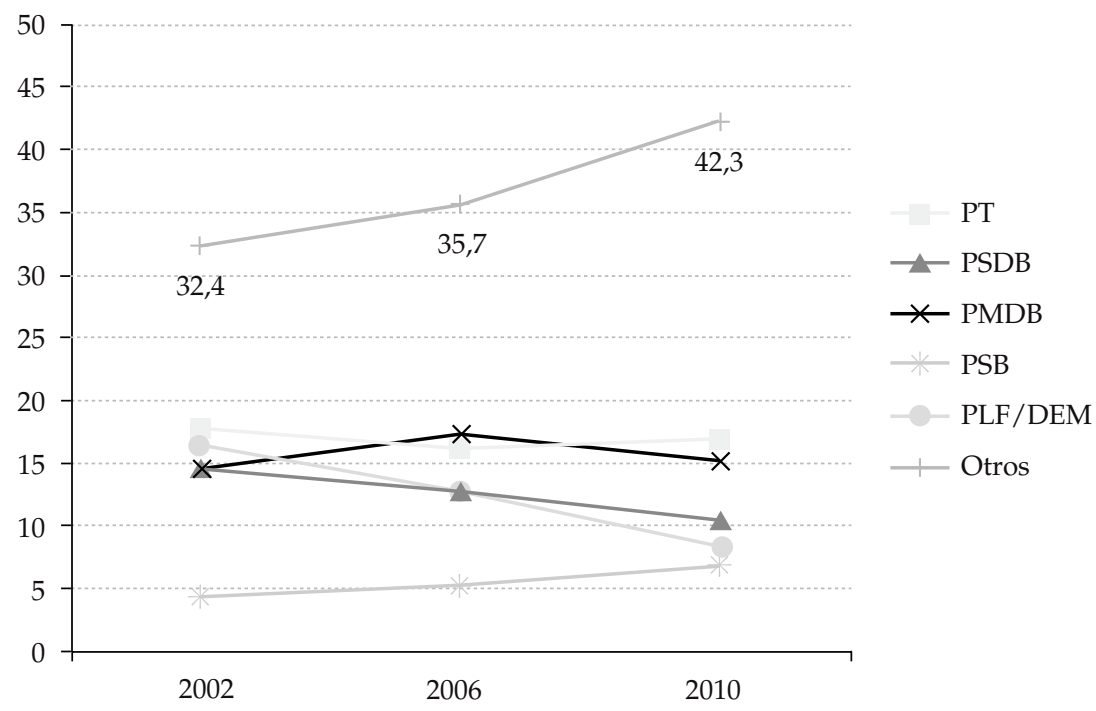

Fuente: elaboración propia, con base en datos de la Cámara de Diputados, disponibles en http:/ / www2.camara.gov.br/deputados/liderancas-e-bancadas/bancada-na-eleicao. [Consulta: 14-03-2012].

6 En el período 2007-2010 estaban representados en el Senado Federal 11 partidos, y en el período 2003-2007 los senadores venían de 13 partidos políticos. Ver los datos en http:/ /www.senado.gov.br/senadores/periodos/ LegisAnter52.shtm y en http://www.senado.gov.br/senadores/periodos/LegisAnter53.shtm. Consulta: 20/03/2012.

7 Partido dos Trabalhadores (PT), Partido do Movimento Democrático Brasileiro (PMDB), Partido Democrático Trabalhista (PDT), Partido Socialista Brasileiro (PSB), Partido da República (PR), Partido Comunista do Brasil (PcdoB), Partido Republicano Brasileiro (PRB), Partido Trabalhista Nacional (PTN), Partido Social Cristão (PSC) y Partido Trabalhista Cristão (PTC).

8 Por ejemplo, no se reeligieron líderes importantes del PSDB, como los senadores Artur Virgilio y Tasso Jereissati. Tampoco se reeligió el senador Marco Maciel (DEM), vicepresidente durante los mandatos de Fernando Henrique Cardoso. 
elegidos y los suplentes que sustituyeron a senadores en otros cargos, el Senado tuvo una significativa renovación de más de la mitad de sus miembros. Así como en la Cámara de Diputados, también en el Senado la renovación fue positiva para el nuevo gobierno. Sin embargo, como veremos, durante el primer año de la presidencia de Dilma Rousseff esas mayorías parlamentarias no fueron utilizadas por el Poder Ejecutivo para aprobar cambios muy profundos.

\section{LA PRESIDENCIA DE DILMA ROUSSEFF: EL PRIMER AÑO}

Las amplias mayorías logradas por la coalición del gobierno en las dos Cámaras del Congreso Nacional permitirían, en principio, ejercer un fuerte control de la agenda legislativa. En el segundo semestre de 2011 la tarea de garantizar mayorías parlamentarias se tornó aún menos difícil gracias a la división del partido de oposición Demócratas y la creación del Partido Social Democrático (PSD). El DEM perdió alrededor de 40\% de sus diputados (17 de 43 elegidos en 2010) y uno de sus seis senadores, además de haber perdido el gobernador de São Paulo, el principal estado del país. Los 47 diputados federales y dos senadores que se afiliaron al recién-creado PSD, aunque no integraron formalmente la base de apoyo al gobierno, se han posicionado a favor del Poder Ejecutivo, en la práctica disminuyendo aún más el tamaño de la oposición (ver Tabla 4). ${ }^{9}$

Aun contando con esa amplia mayoría en las dos casas del Congreso Nacional, la presidenta Dilma Rousseff optó por una agenda relativamente tímida de iniciativas legislativas. Dicha agenda puede ser analizada empíricamente a partir de la producción institucional del Poder Ejecutivo, es decir, a través del análisis de propuestas de enmienda constitucional, medidas provisorias, proyectos de ley y proyectos de ley complementaria. La Tabla 4 compara el número de iniciativas del primer año del primer mandato de Luiz Inácio Lula da Silva y el primer año de mandato de Dilma Rousseff.

Tabla 3: Iniciativas del Poder Ejecutivo en Primer Año de Mandato Presidencial (2003 y 2011) (número de iniciativas)

\begin{tabular}{lcc}
\hline Iniciativa & 2003 & 2011 \\
\hline Proyecto de Ley del Ejecutivo & 32 & 27 \\
Proyecto de Ley Complementaria & 3 & 1 \\
Propuesta de Enmienda Constitucional & 2 & 2 \\
Medida Provisoria & 58 & 36 \\
\hline
\end{tabular}

Fuente: www.relacoesinstitucionais.gov.br. [Consulta: 12-02-2012]

9 El ejemplo más significativo fue la votación de una de las materias potencialmente más polémicas del año, la llamada "desvinculación de las recetas de la Unión", una propuesta de enmienda constitucional que mantiene la discrecionalidad del gobierno para gastar 20\% de la recaudación federal. Aunque vigente desde 1994, esa medida es polémica por la flexibilidad presupuestaria ganada por el Poder Ejecutivo. 
Tabla 4: Bancadas de los Partidos Políticos en la Cámara de Diputados y en el Senado Federal en diciembre del 2011 (por número de parlamentarios y \% del total; en negritas los partidos que votaron con el gobierno en más de dos tercios de las votaciones)

\begin{tabular}{|c|c|c|c|c|}
\hline \multirow{2}{*}{ Partido Político } & \multicolumn{2}{|c|}{ Cámara de Diputados } & \multicolumn{2}{|c|}{ Senado Federal } \\
\hline & Número & $\%$ & Número & $\%$ \\
\hline PT & 86 & 16,76 & 13 & 16,05 \\
\hline PMDB & 77 & 15,01 & 18 & 22,22 \\
\hline PSDB & 52 & 10,14 & 10 & 12,35 \\
\hline PSD & 47 & 9,16 & 2 & 2,47 \\
\hline PP & 38 & 7,41 & 5 & 6,17 \\
\hline PR & 36 & 7,02 & 7 & 8,64 \\
\hline PSB & 29 & 5,65 & 4 & 4,94 \\
\hline DEM & 27 & 5,26 & 5 & 6,17 \\
\hline PDT & 26 & 5,07 & 5 & 6,17 \\
\hline РТВ & 21 & 4,09 & 6 & 7,41 \\
\hline PSC & 17 & 3,31 & - & - \\
\hline PcdoB & 13 & 2,53 & 2 & 2,47 \\
\hline PPS & 11 & 2,14 & - & - \\
\hline PV & 10 & 1,95 & 1 & 1,23 \\
\hline PRB & 10 & 1,95 & 1 & 1,23 \\
\hline PtdoB & 3 & 0,58 & 1 & 1,23 \\
\hline PSOL & 3 & 0,58 & - & - \\
\hline PMN & 2 & 0,39 & - & - \\
\hline PHS & 1 & 0,19 & - & - \\
\hline PRTB & 1 & 0,19 & - & - \\
\hline PRP & 1 & 0,19 & - & - \\
\hline PTC & 1 & 0,19 & - & - \\
\hline PSL & 1 & 0,19 & - & - \\
\hline Sin partido & - & - & 1 & $1,23 \%$ \\
\hline Total & 513 & 100 & 81 & 100 \\
\hline
\end{tabular}

Fuente: elaboración propia a partir de datos disponibles en www.camara.gov.br y senado. gov.br. [Consulta: 12-03-2012]

La comparación del número de iniciativas en 2003 y 2011 pareciera confirmar una estrategia más tímida por parte de la nueva Presidenta. Un análisis que va más allá de los números para ver el contenido de esos cambios, muestra que en realidad hay muchas similitudes en las estrategias utilizadas por Dilma en 2011 y Lula en 2003. Si hacemos una diferenciación entre actos de innovación institucional (que crean nuevas reglas en términos de políticas o programas que no existían antes), cambios incrementales (que promueven cambios en políticas o programas que ya existen) y actos administrativos (por 
ejemplo, en el ámbito presupuestario y de recursos humanos), vemos que los primeros tuvieron un peso pequeño en el total tanto en el 2003 como en el 2011 (ver Tablas 5 y 6).

Tabla 5: Iniciativas del Poder Ejecutivo enviadas al Congreso Nacional, por objetivo (2003 y 2011) (\% del total)*

\begin{tabular}{lcc}
\hline Objetivo & 2003 & 2011 \\
\hline Innovación institucional & 15 & 17 \\
Cambios incrementales & 23 & 23 \\
Actos administrativos & 62 & 60 \\
\hline
\end{tabular}

*Proyectos de ley (ordinarios y complementarios) y propuestas de enmienda a la Constitución. Fuente: elaboración propia a partir de datos disponibles en www2.camara.gov.br/atividadelegislativa. [Consulta: 12-03-2012]

Tabla 6: Medidas provisorias enviadas al Congreso Nacional, por objetivo (2003 y 2001) (\% del total)

\begin{tabular}{lcc}
\hline Objetivo & 2003 & 2011 \\
\hline Innovación institucional & 12 & 8 \\
Cambios incrementales & 60 & 33 \\
Actos administrativos & 28 & 59 \\
\hline
\end{tabular}

Fuente: elaboración propia a partir de datos disponibles en www2.camara.gov.br/atividadelegislativa. [Consulta: 12-03-2012]

Tabla 7: Comparación de Indicadores Económicos en 2010 y 2011

\begin{tabular}{ccccc}
\hline Año & $\begin{array}{c}\text { Variación del Producto } \\
\text { Interno Bruto (\%) }\end{array}$ & $\begin{array}{c}\text { Tasa de } \\
\text { Inflación (\%) }\end{array}$ & $\begin{array}{c}\text { Variación de la Producción } \\
\text { Industrial (\%) }\end{array}$ & $\begin{array}{c}\text { Empleos } \\
\text { creados (miles) }\end{array}$ \\
\hline 2010 & 7,5 & 5,9 & 10,5 & 2.137 \\
2011 & 2,7 & 6,5 & 0,3 & 1.566 \\
\hline
\end{tabular}

Fuente: Ministerio da Fazenda (2012) y Mantega (2012).

Es decir, tanto Lula como Dilma utilizaron sus primeros años en el poder para organizar el gobierno. También es cierto que en esos dos años el problema de la estabilidad macroeconómica fue tema prioritario en la agenda del gobierno, que utilizó actos administrativos para hacer cambios en las políticas fiscal, monetaria y cambiaria. En 2011, como se puede ver en la Tabla 7, hubo una desaceleración importante de la economía en comparación con el año anterior y una tendencia al alza de la inflación, sobre todo en el primer semestre. 
El resultado de un contexto económico y político delicado es que el primer año de la presidencia de Dilma Rousseff es caracterizado por una estrategia que prioriza los cambios administrativos y los cambios incrementales. Quizás el mejor ejemplo de cambio incremental en materia de políticas públicas sea el programa "Brasil sin miseria", lanzado en junio del 2011. Ese programa, que tiene como objetivo combatir la pobreza extrema, mezcla la continuidad de iniciativas de política social de los años anteriores, como el "Beca Familia", con nuevos programas como el "Plan Vivir sin Límites" (para personas con deficiencias) y el "Beca Verde" (da beneficios a familias en situación de extrema pobreza que desarrollen proyectos de conservación ambiental). Para su implementación, el Poder Ejecutivo envió dos proyectos de ley y una medida provisoria al Congreso Nacional. Esos programas son considerados fundamentales para mantener la tendencia a la caída de la desigualdad en el país (ver Gráfico 3).

Sin embargo, en el 2011 la Presidencia no utilizó su poder de agenda ni sus amplias mayorías parlamentarias para aprobar temas más polémicos, como la reforma política (especialmente en lo que se refiere al funcionamiento del sistema electoral y a las reglas para el financiamiento de las campañas), la reforma tributaria o la regulación de los medios de comunicación, todos ellos temas centrales del programa del Partido dos Trabalhadores. ${ }^{10}$

Es imposible comprender la estrategia del Poder Ejecutivo sin considerar las peculiaridades del "presidencialismo de coalición" brasileño. La necesidad de construcción de amplias coaliciones en un contexto de gran fragmentación en el Poder Legislativo lleva a la

Gráfico 3: Evolución del Índice de Gini en Brasil, 1960-2012

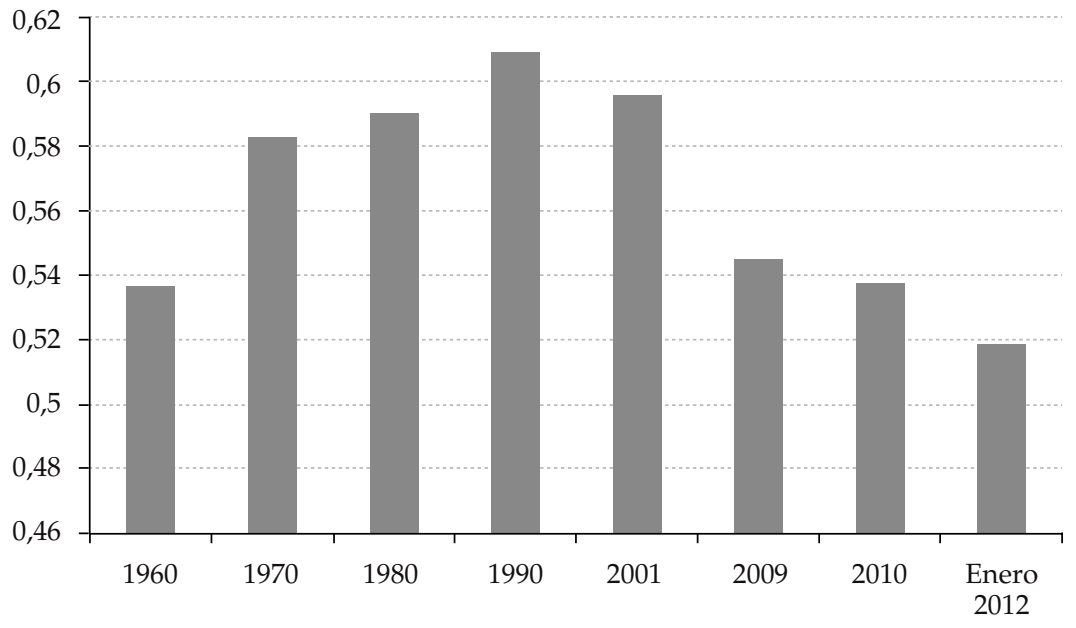

Fuente: Centro de Políticas Sociais/FGV (2012), en base a datos del Instituto Brasileiro de Geografia e Estatística (IBGE).

10 Ver, por ejemplo, la resolución política aprobada en el cuarto congreso extraordinario del PT, realizado en 2011 (Partido dos Trabalhadores, 2011). 
construcción de gabinetes heterogéneos (en los cuales suelen coincidir líderes partidarios que defienden posiciones no siempre coincidentes en temas claves de políticas públicas) y de mayorías legislativas cuya fidelidad se puede poner en cuestión en momentos de crisis $^{11}$. Así, no es de sorprender que los puestos de ministro del gobierno de Dilma Rousseff hayan sido distribuidos inicialmente entre nada menos que siete partidos políticos. Ese rompecabezas de la construcción de gobernabilidad también incluye la distribución de puestos adentro de los ministerios y de puestos directivos en empresas estatales, las cuales son muy disputadas porque a veces tienen un presupuesto más grande que los ministerios.

Así, la ausencia de una agenda muy innovadora se explica, como se argumentó al principio, tanto por la opción política por la continuidad como por las dificultades de hacer grandes cambios a partir de una coalición gobernante tan heterogénea. Es posible imaginar que al menos algunos de los temas polémicos mencionados generan tanta o más discordancia dentro del gobierno que entre gobierno y oposición. Ese no es un problema enfrentado solamente por el gobierno de Dilma Rousseff, sino que es parte de la lógica de creación de coaliciones de gobierno en un contexto de presidencialismo de coalición (Lemos, 2011: 166).

Dos innovaciones constituyen excepciones y merecen ser mencionadas en este análisis inicial del gobierno Dilma. En ambos casos el debate estuvo relacionado con el tema de la dictadura militar: la creación de la Comisión de la Verdad, que investigará los crímenes ocurridos durante la dictadura militar (1964-1985), y la nueva ley de acceso a la información, que terminó con el sigilo eterno de documentos y permitirá que los actos secretos de los presidentes y documentos relacionados al período militar se hagan públicos. En los dos casos, la mayor parte de la base gobernante votó con el Poder Ejecutivo, pero con disenso de algunos parlamentarios oficialistas y la adhesión de algunos de la oposición, demostrando que para algunos temas la línea divisoria entre los dos campos políticos puede ser fluida.

Volviendo a la comparación entre la nueva Presidenta y su antecesor, hay alguna evidencia -todavía no analizada por los cientistas políticos- de que hay profundas divergencias en términos de gestión y, en especial, de la relación entre la Presidencia y los partidos políticos y los parlamentarios de la base de gobierno. Según Claudio Couto, Dilma Rousseff tiene un estilo personal bastante diferente al liderazgo "popular" y "exuberante" (Couto, 2011: 160-1) que caracterizaba la actuación de su predecesor.

Por ahora, lo que sabemos es que el nuevo gobierno ha sido bien evaluado en las encuestas de opinión. De hecho, una encuesta realizada en diciembre del 2011 mostró que el $72 \%$ de los entrevistados aprobaban la actuación de la presidenta, número más alto que los alcanzados por los ex presidentes Luiz Inácio Lula da Silva y Fernando

11 Hay una amplia literatura sobre el presidencialismo de coalición y sus consecuencias. En particular, hay un debate todavía en abierto sobre sus impactos en las relaciones entre el Poder Ejecutivo y el Poder Legislativo, que va más allá de los objetivos de este texto. El concepto original es de Abranches (1988). La visión predominante en la ciencia política brasileña es la de Figueiredo y Limongi (1999). Rennó (2006), Power (2010) y Lassance (2010) ofrecen un panorama del debate. 
Henrique Cardoso en la misma época de sus primeros años de mandato. El gobierno fue evaluado como bueno u óptimo por el $56 \%$, el mejor número después del primer año de mandato desde que empezó la encuesta (en 1995). Por otra parte, la mayor parte de los entrevistados desaprobó la actuación gubernamental en seis áreas claves de políticas públicas, incluyendo salud, seguridad pública y educación. ${ }^{12}$

\section{CONSIDERACIONES FINALES}

En un continente marcado en su historia por crisis institucionales periódicas, rupturas autoritarias y la aparición de líderes a los que les gusta adoptar la política de "tierra arrasada", llama la atención que, en el caso brasileño, una presidenta haya sido elegida en base a un discurso que prometía continuidad. En la medida en que dicha continuidad es opción y estrategia política, tiene una connotación positiva. Sin embargo, en la medida en que, por dificultades derivadas del funcionamiento del sistema político, deja de poner en la agenda cambios necesarios para el país, adquiere una connotación que puede ser negativa.

Ese es el desafío del gobierno de Dilma Rousseff: aprovechar y profundizar los cambios del pasado, sobre todo en lo que refiere a llenar el "casillero vacío", y a la vez lograr implementar una agenda de cambios que permitan avanzar más. En ese sentido, una incógnita importante es si en el 2012 se podrá dejar a un lado la política de contención de gastos implementada en el 2011, en favor de una política de aceleración del crecimiento económico.

Como vimos, la estrategia de la Presidencia a lo largo del 2011 tuvo muchas similitudes con relación al primer año de mandato del presidente Lula, en 2003, destacándose las pocas innovaciones institucionales, concentradas en el combate a la pobreza y el control de la inflación y de los gastos públicos. Sin embargo, el 2011 también fue marcado por las sucesivas denuncias de corrupción en contra de miembros del gabinete y, consecuentemente, mucha energía se gastó para dar respuestas a esas crisis internas. La relación con el Poder Legislativo no fue objeto de muchas tensiones, pero también es cierto que el Poder Ejecutivo no presentó medidas muy polémicas. Todavía no se ha puesto a prueba la estabilidad de la base parlamentaria del gobierno.

Más allá de las evidentes diferencias de personalidad de Dilma Rousseff y Luiz Inácio Lula da Silva, la reacción más decisiva frente a acusaciones de corrupción de miembros del gobierno, la presencia más fuerte del PT en su gabinete que en el gobierno anterior, la mayor participación de mujeres en el gabinete (8 en un total de 37 ministerios, una proporción inédita) y la mayor distancia impuesta entre la Presidenta y los parlamentarios son todos indicios de cambios de gestión y de forma de articulación entre los poderes.

12 La encuesta fue realizada por el lbope con 2.002 personas en 141 municipios del país y tiene margen de error de dos puntos percentuales. Ver http://clippingmp.planejamento.gov.br/cadastros/noticias/2011/12/17/ dilma-bate-popularidade-de-lula-e-fh-no-1o-ano. [Consulta: 12-02-2012] 
El significado de esas diferencias y sus posibles impactos en el gobierno son cuestiones a ser analizadas en los anuarios políticos de los próximos años.

\section{REFERENCIAS}

Centro de Políticas Sociais/FGV. 2012. "De volta ao país do futuro: projeções, crise européia e a nova classe média". Rio de Janeiro: Fundação Getúlio Vargas. [En línea] http://cps.fgv.br/ncm2014 [Consulta: $16 / 03 / 2012]$.

Couto, Cláudio Gonçalves. 2011. "O governo Lula e as perspectivas de Dilma Rousseff", Iberoamericana XI(41): 159-163.

Datafolha. 2010. “Eleições 2010". [En línea] http:/ /datafolha.folha.uol.com.br/eleicoes/2010/2010_index. php [Consulta: 12-03-2012]

Fajnzylber, Fernando. 1989. "Industrialización en América Latina: de la 'caja negra' al 'casillero vacío': comparación de patrones contemporáneos de industrialización". Cuadernos de la CEPAL, núm. 60, CEPAL: Santiago, Chile.

Figueiredo, Argelina y Fernando Limongi. 1999. Executivo e Legislativo na nova ordem constitucional. Rio de Janeiro: FGV.

Fleischer, David. 2010. “The Brazilian elections on 3 October 2010: the campaign and the first round results", trabajo presentado en el Congreso Internacional de la Latin American Studies Association, Toronto, 6-9 de octubre.

Fleischer, David. 2011. "Attempts at political reform in Brazil: a never-ending story", Center for Hemispheric Policy, University of Miami, 29 de noviembre.

IPEA. 2012. “Índice de Expectativas das Famílias", 17ª . Edición, Brasília: Instituto de Pesquisa Econômica Aplicada, enero.

Lassance, Antonio. 2010. "Poder Executivo: configuração histórico-institucional". In: Estado, instituições e democracia: República, editado por A. Cunha, B. Abreu de Medeiros y L. C. de Aquino, Brasília: IPEA, vol. 1, pp. 65-95.

Latinobarómetro. 2011. “Informe Latinobarómetro 2011" [En línea] www.latinobarometro.org [Cosulta: 10-02-2012]

Lemos, Leany Barreiro. 2010. "The new president and the new Congress 2011: challenges ahead", trabajo presentado en la conferencia "Brazil in the world context: challenges and perspectives", Freie Universität, Berlin, 4 de febrero.

Lemos, Leany Barreiro. 2011. “As eleições de 2011 e os desafios da nova presidenta do Brasil”, Iberoamericana XI(41): 164-169.

Limongi, Fernando y Rafael Cortez. 2010. "As eleições de 2010 e o quadro partidário", Novos Estudos Cebrap 88: 21-37.

Melo, Carlos Ranulfo. 2007. “Nem tanto ao mar, nem tanto à terra: elementos para uma análise do sistema partidário brasileiro. In: A democracia brasileira: balanço e perspectivas para o século 21, editado por C. Melo y M. Alcántara. Belo Horizonte: Editora da UFMG, pp. 374-404.

Meneghello, Rachel. 2007. "Tendências eleitorais ao fim de 21 anos de democracia". In: A democracia brasileira: balanço e perspectivas para o século 21, editado por C. Melo y M. Alcántara. Belo Horizonte: Editora da UFMG, pp. 267-302.

Mantega, Guido. 2012. "Desafios do crescimento num cenário de crise global”. Presentación en el Comisión de Asuntos Económicos del Senado Federal, Brasília, 13 de marzo. [En línea] http:/ /www.fazenda. gov.br/ [Consulta: 16-03-2012].

Ministério da Fazenda. 2012. "Economia brasileira em perspectiva", 14 a edición especial, Brasília, febrero. [En línea] http:/ /www.fazenda.gov.br/ [Consulta: 16-03-2012].

Peixoto, Vitor y Lúcio Rennó. 2011. "Mobilidade social ascendente e voto: as eleições presidenciais de 2010 no Brasil", Opinião Pública, 17(2): 304-332.

Pierucci, Antônio Flávio. 2011. "Eleição 2010: desmoralização eleitoral do moralismo religioso". Novos Estudos CEBRAP 89: 6-15. 
Powell, Larry y Eduardo Neiva, E. 2006. "The Pharisee Effect: When religious appeals go too far". Journal of Communication and Religion, 29:70-102.

Power, Timothy J. 2010. "Optimism, Pessimism, and Coalitional Presidentialism: debating the institutional design of Brazilian democracy". Bulletin of Latin American Research, 29(1): 18-33.

Partido dos Trabalhadores. 2011. "Resolução política aprovada no quarto congresso extraordinário do Partidos dos Trabalhadores", [En línea] http://www.pt.org.br/downloads/categoria/resolucoes_ do_4_congresso. [Consulta: 16-03-2012].

Rennó, Lúcio. 2006. “Críticas ao presidencialismo de coalizão". In: Reforma política no Brasil, editado por L. Avritzer y F. Anastasia. Belo Horizonte: Ed. UFMG/PNUD, pp. 259-271.

Skowronek, Stephen. 1983. The politics presidents make: leadership from John Adams to George Bush. Cambridge: Harvard University Press.

Skowronek, Stephen. 2003. "Presidential leadership in political time". In: The presidency and the political system, editado por N. Michael, 8 a edición, Washington: CQPress, pp. 89-135.

Marisa von Bülow. Profesora del Instituto de Ciencia Política de la Pontificia Universidad Católica de Chile y profesora (ausente con permiso) del Instituto de Ciencia Política de la Universidad de Brasilia. Email: marisavonbulow@uc.cl

Antonio Lassance. Investigador del Instituto de Pesquisa Económica Aplicada de Brasil y estudiante de doctorado del Instituto de Ciencia Política de la Universidad de Brasilia.

Email: antoniolassance@ipea.gov.br 